\title{
Towards inclusive migrant healthcare
}

\author{
Denise Spitzer and colleagues argue that improving the health and wellbeing of migrants \\ requires attention to their diverse circumstances and building inclusive healthcare
}

T he number of migrants moving within and across borders of nation states for work, resettlement, and refuge is unprecedented. The legal and discursive categorisation of migrants, and their social status, affect the health services open to them and relations with providers. Establishing more inclusive migrant healthcare is critical to supporting health as a human right regardless of migratory status.

\section{Migrants}

Adoption of managed migration frameworks by many countries has led to a proliferation of immigration categories. These are based on skills, age, nationality, and income. The term migrant includes 258 million international immigrants who permanently or temporarily settle in another country $^{1}$; 3.1 million asylum seekers who are fleeing persecution and violence; 25.4 million refugees who have been granted asylum; and 40 million internally displaced people who have sought refuge within the borders of their nation state. $^{2}$

Each immigration category has specific requirements. These focus apparently on the labour market potential, with people in each category being granted explicit rights. ${ }^{3}$ Immigration policies determine

\section{KEY MESSAGES}

- Numbering over 326 million, migrants are heterogeneous and are individually and collectively affected by a range of factors that affect health and their access to, and experiences of, healthcare

- Migrant healthcare cannot be isolated from historical, sociopolitical, economic, and legal contexts, and racism and othering that frame how individuals and organisations respond to diverse groups of migrants

- Inclusive migrant healthcare requires building on individual and community strengths, promoting community oriented, participatory practices, increasing the diversity of the health workforce, carrying out structural analysis, and ensuring competency in planning, policy, and practice which migrants may enter a country and for how long they may stay; where they can work (and live); if they can be accompanied by, or reunited with, family members; and whether they can have access to health and social services.

Migrants move for a number of reasons. Their legal standing may change, and thus migrant categorisations are regularly blurred. Some people fleeing civil upheaval may be able to secure employment in another country and enter as an immigrant, whereas others with no job prospects may become refugees. Moreover, status can change in ways that migrants may or may not want. For example, an asylum seeker might become a refugee, or a labour migrant might become an undocumented worker.

Perceptions of migrants are increasingly influenced by racism and xenophobia. ${ }^{4}$ This contributes to increasingly restrictive policies for all forms of migration. Calamities forcing people to leave their homelands affect all social strata. However, refugees and asylum seekers are often portrayed as unskilled, uneducated, and ungrateful, and temporary foreign workers are often accused of undercutting local labour. ${ }^{34}$ The way in which migrants are perceived by the public greatly affects the formal policies that govern their movements and entitlements, and how they are received personally and socially. This has a large effect on the health of migrant populations.

\section{Intersectionality and migrant health}

Intersectionality insists that human experience is rooted in social location and influenced by historical and geographical considerations and thus cannot be reduced to single markers. Instead it allows us "to speak about simultaneity and mutual coconstitution of different categories of social differentiation and to emphasise the specificity of the experiences shaped by these interactions." 5 As a result of interactions among socioeconomic classes, gender, ethnicity, indigeneity, and migration status, among many other factors, individuals can experience the effects of both multiple oppressions and privilege and may have access to personal, material, and social resources to counter them. ${ }^{67}$

Position within the social hierarchyshaped by geography, political economy, and history-structures access to healthcare. Genetic inheritance and place in the social hierarchy affect individual and collective interactions with physical and social environments throughout life. This influences exposure to bio-psychosocial insults (including racism, sexism, and homophobia) and shapes access to personal and social resources with which to withstand them (box 1). ${ }^{11}$ These intersections contribute to differentiated health outcomes.

Intersectionality uncovers the multiple ways that migration status, including the rigours of travel, changes in social roles, supports, and location, affect health. The placement of migrants into temporary, permanent, or undocumented categories (often determined by divisions of labour according to gender and racialised status) affects their exposure to risks and access to health determinants, including healthcare. $^{12}$

In many countries, skilled professionals and investors-often men of a higher socioeconomic class-are eligible for permanent resettlement, whereas domestic and agricultural workers and labourers-primarily racialised women and men-are prohibited from settling in area where they may have lived for years. The precariousness of their residency is often an echo of their experiences with precarious work, described as 3D "dirty, demanding, and dangerous." 13 These jobs are characterised by low wages, poor occupational safety measures, job insecurity, lack of control over work processes, and exclusion from protective legislation, contributing to deleterious health outcomes. ${ }^{14}$ Overcrowded workers' residences where occupants are at risk of contracting infectious diseases, or where they are confined to workplaces (fishing boats, agricultural estates, and private households), or where they are reliant on employers for food and access to 


\section{Box 1| Migration and risk of abuse}

Migration status and other components of intersectionality are implicated in exposure to violence and its health effects. Racism and the loss of traditional male roles owing to migration threaten masculinity-previously expressed through power status in the family and economic independence. This seems to create a situation in which women are more vulnerable to domestic violence. ${ }^{8}$ In Canada and the UK, precarious migration status engendered by sponsorship agreements often position women as dependent on male partners. This may inhibit women from leaving an abusive partner as they may be unaware that leaving will not jeopardise their applications for permanent status. ${ }^{910}$

healthcare, and often subject to constant surveillance, are also problematic. ${ }^{1315}$

These effects are exacerbated by conditions external to paid employment. The dynamics of downward social mobility ${ }^{16}$ and changes to gendered household roles, including breadwinning and parenting responsibilities that may challenge traditional gender identities ${ }^{17}$ or compel individuals to assume additional duties, have significant repercussions for exposure to stress and to health. ${ }^{18}$ Gendered strategies for those dealing with material deprivation appear to produce disparate trends in morbidity and mortality. Men may have conditions related to violence and consumption of alcohol and tobacco, whereas women, who tend to internalise stress, present with more heart disease and diabetes. ${ }^{19}$ Intersectionality allows a more nuanced understanding of the complexity of the problems presented, and identification of more appropriate solutions.

\section{Accessing services and patient-provider interactions}

Legal status determines the type and quality of health services and social protection available to migrants. ${ }^{20}$ Most often access is poor, ${ }^{20}$ although Uganda offers refugees access to health services equal to that of the native-born population, together with free primary education and a plot of land. ${ }^{21}$ In some countries, reception is less welcoming. Temporary foreign workers may be returned to their countries of origin when they become ill or injured on the job, compelling their families, communities, and local health authorities to absorb the economic and social costs. ${ }^{22}$

Barriers to care often persist despite legal rights. ${ }^{23}$ Fearing detention or deportation by health authorities, undocumented asylum seekers and labour migrants often depend on services provided by civil society. Labour migrants residing with their employers may rely on them to access health services. Obtaining sexual and reproductive health services can be problematic for women, particularly where pregnancy may result in job loss and deportation. ${ }^{24}$ Underuse of healthcare, often due to restricted status, work environments, or lack of information, may have a significant effect on public health: failure to treat communicable diseases may lead to further spread while untreated chronic conditions may lead to deterioration and increased costs.

The disparate and often shifting eligibility criteria can be confusing for health professionals, institutions, and patients. Health and service providers are bound by local social and political conditions that shape which migrants they can see and which services they can offer. At the same time they must try to adhere to the professional and ethical guidelines that frame their practice.

Migrants' interactions with healthcare providers can be further complicated by language barriers and unfamiliarity with local procedures, as even biomedical practice is not uniform. Differences in expectations and knowledge reduce opportunities to develop mutual understanding of complaints and treatments. ${ }^{25}$

These individual interactions are embedded in systems of racism among other forms of discrimination based on gender, sexuality, dis/ability, religion, age, etc that structure opportunity and engender inequality. ${ }^{26-28}$ Media and political narratives that link migration to terrorism, insecurity, and other social ills have hardened attitudes towards marginalised populations. This increases public pressure against migrants' access to, and use of, services. Othering-a social process (re)produced by those in power that ascribes difference-links systemic and interpersonal biases, affects dignity and quality of life, and reduces access to services for minority communities. ${ }^{4}$

\section{Towards inclusive migrant care}

While knowledge of successful practices to improve migrant health is limited, insights into good practice are emerging (box 2). Engagement with diverse stakeholders, including migrants, is critical to developing promising strategies for the implementation of appropriate migrant healthcare. ${ }^{29} 30$ The culture of organisations and the attitudes and values reflected in policies, practice, and displayed by leaders affect service users, who must be welcomed and treated with dignity. ${ }^{4}$ Listening to the voices of workers, providers, and users of services is integral to facilitating more equitable healthcare. The use of peer mentors in interventions that move beyond a focus on disease has also proved to be beneficial in the promotion of health and wellbeing. ${ }^{26}$ In South Africa, refugee physicians are allowed to practise in public sector facilities provided that they work for a year in an underserved community. ${ }^{21}$ Turkey has enabled Syrian refugee physicians to provide care for their compatriots. ${ }^{31}$ Although investments must be made in training to ensure that migrant staff meet local practice standards, these initiatives offer great benefits to the local population and migrant professionals.

Furthermore, efforts of local physicians are integral to enhancing migrant health in both public and private interactions. For example, Canadian physicians rallied to reinstate health benefits to refugees and claimants, ${ }^{32}$ and Australian healthcare providers have been demanding better access to care for immigrants in detention. ${ }^{33}$ It is vital to incorporate social history taking and structural analysis to uncover the impact of migratory status and other factors that contribute to ill health, and which may also impede recovery. ${ }^{28}{ }^{34}$ Structural competency, defined as "the trained ability to discern how a host of issues defined clinically as symptoms, attitudes, or diseases... represent the downstream implications of a number of upstream decisions," ${ }^{34}$ should be incorporated in medical education.

Harnessing the skills of migrants to enhance health services may also help to deal with poor distribution or lack of health providers. Such diversity in the health workforce is important for fostering inclusive migrant health. Community health workers have improved migrant health in a host of countries. They are drawn from marginalised populations and are committed to working with them. Their knowledge of communities and the connections and the trust they develop with the community, are their biggest strengths. ${ }^{35}$ Community health workers need opportunities for workforce development, access to financing, occupational regulation, and recognition by other professionals. ${ }^{35}$ Their position on 


\section{Box 2 | Canada's Multicultural Health Brokers Cooperative}

In Edmonton, Canada, the Multicultural Health Brokers Cooperative helps migrant families understand how to navigate available health and social services and to explore culturally affirming practices in social service, educational, and public health settings. As community health workers and fellow migrants, health brokers deliver programmes to around 2300 migrant families from 80 countries who speak 30 different languages. Programming includes perinatal outreach and support to expectant mothers and newborns and mentorship, leadership, and mental health programmes for youth. The cooperative's ultimate goal is to attain optimum health, equity, and social justice for migrants and to promote system change (www.mchb.org).

the margins of the workforce makes their work complex, competitive, and uncertain. Meaningful inclusion of community health workers in all aspects of policy making and decision processes is required. ${ }^{36}$

Formal and informal networks are also important mechanisms for improving migrant health by establishing health alliances or expanding the options for dealing with migrant health. ${ }^{37}$ Working in coalition with networks that include migrant resource centres, trade unions, advocacy, and human rights organisations, can facilitate outreach and mutual learning. Migrant resource centres have been established through the efforts of migrants, often employing local and transnational networks. ${ }^{38}$ They offer services and facilitate migrants' access to healthcare-often regardless of documented status. Organisations such as the Farmworker Health Network in the USA, the Multicultural Coalition for Equity in Health in Canada, and the Mission for Migrant Workers in Hong Kong, operate with assistance from public and private partners. These coalitions aim to reduce adverse social determinants of health and offer innovative sites for launching interventions at the workplace and in the community.

Critically, inclusive migrant healthcare must be based on a multisectoral approach that includes health, social services, housing, education, and immigration systems, attending not just to the social determinants of health but to the social determinants of equity ${ }^{27}$

\section{Conclusion}

Although the underlying political, economic, social, and environmental factors that lead to migration must be dealt with, we have an obligation and opportunity to support the health and wellbeing of migrants.

Health is a human right that transcends borders and juridical categorisations. Improving the wellbeing of the world's migrants requires an intersectional lens that focuses on the diverse circumstances and locations in which migrants are situated. Empirically informed, community centred, culturally adapted intervention models that involve migrants will advance their healthcare.

We thank Ramon Bultron, Asia-Pacific Mission for Migrants, in Hong Kong for his comments on our draft manuscript.

Contributors and sources: DLS has more than 20 years' experience of conducting research with migrant populations around the world and was the primary instigator, coordinator, and writer of this article. ST is a social worker with a PhD in population health and contributed to the discussion of community health workers and to sections on intersectionality and violence. $A B Z$ is a global health specialist interested in migrant populations, health, and human rights and provided content on othering and examples of migrant care. ENK is a sociologist with a focus on global health equity and gave input into promising practices and knowledge gaps. EP is a professor of nursing who has conducted research with marginalised populations and provided examples of migrant advocacy in health services. All authors reviewed, commented on, and approved the final manuscript. DLS is the guarantor.

Competing interests: We have read and understood BMJ policy on declaration of interests and have no relevant interests to declare.

Provenance and peer review: Commissioned; externally peer reviewed.

This article is part of a series developed by The BMJ, the UN Migration Agency (IOM), and the Migration Health and Development Research Network (MHADRI) The article was commissioned by The BMJ, which retained full editorial control over external peer review, editing, and publication of these articles. Open access fees for the initial articles in the series were funded by IOM and Bruyère Research Institute. Denise L Spitzer, professor ${ }^{1}$

Sara Torres, assistant professor ${ }^{2}$

Anthony B Zwi, professor of global health and development ${ }^{3}$

Ernest Nene Khalema, dean and head of school ${ }^{4}$

Erlinda Palaganas, professor ${ }^{5}$

${ }^{1}$ School of Public Health University of Alberta, Canada ${ }^{2}$ School of Social Work, Laurentian University, Canada ${ }^{3}$ School of Social Sciences, University of New South Wales, Australia

${ }^{4}$ School of Built Environment and Development Studies, University of Kwa-Zulu Natal, South Africa

${ }^{5}$ College of Social Sciences, Institute of Management, University of the Philippines-Baguio, Philippines

Correspondence to: D LSpitzer

spitzer@ualberta.ca

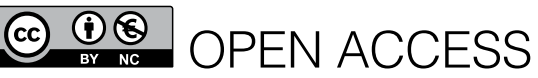

This is an Open Access article distributed in accordance with the Creative Commons Attribution Non Commercial (CC BY-NC 4.0) license, which permits others to distribute, remix, adapt, build upon this work non-commercially, and license their derivative works on different terms, provided the original work is properly cited and the use is non-commercial. See: http://creativecommons.org/ licenses/by-nc/4.0/.

\section{Check for updates}

1 UNDESA. Population facts. United Nations Department of Economic and Social Affairs, 2017. https://www.un.org/en/development/ desa/population/publications/pdf/popfacts/ PopFacts_2017-5.pdf

2 UNHCR. Global trends: forced displacement 2017. UNHCR, 2017. https://www.unhcr.org/uk/statistics/ unhcrstats/5b27be547/unhcr-global-trends-2017. html

3 Castles S. Migration, crisis, and the global labour market. Globalizations 2011;8:311-24. doi:10.1080 14747731.2011.576847

4 Grove NJ, Zwi AB. Our health and theirs: forced migration, othering, and public health. Soc Sci Med 2006;62:1931-42. doi:10.1016/j. socscimed.2005.08.061

5 Lutz H, Vivar M, Supik L. Framing intersectionality: an introduction. In: Lutz H, Vivar M, Supik L, eds. Framing intersectionality: debates on a multi-faceted concept in gender studies. Routledge, Taylor and Francis Group, 2016:17-42.

6 Hankivsky O, Reid C, Cormier R, et al. Exploring the promises of intersectionality for advancing women's health research. Int J Equity Health 2010;9:5. doi:10.1186/1475-9276-9-5

7 Hankivsky O. Women's health, men's health, and gender and health: implications of intersectionality. Soc Sci Med 2012;74:1712-20. doi:10.1016/j. socscimed 2011.11.029

8 Fisher C. Changed and changing gender and family roles and domestic violence in African refugee background communities post-settlement in Perth, Australia. Violence Against Women 2013;19:833-47 doi:10.1177/1077801213497535

9 Anitha S. Legislating gender inequalities: the nature and patterns of domestic violence experienced by South Asian women with insecure immigration status in the United Kingdom. Violence Against Women 2011;17:1260-85. doi:10.1177/1077801211424571

10 Steele LS, Lemieux-Charles L, Clark JP, Glazier RH. The impact of policy changes on the health of recent immigrants and refugees in the inner city. $\mathrm{A}$ qualitative study of service providers' perspectives Can I Public Health 2002;93:118-22.

11 Spitzer DL. Engendered movements: migration, gender, and health in a globalized world. In: Gideon J, ed. Handbook on gender and health. Elgar, 2016: 251-67. doi:10.4337/9781784710866.00027

12 Dejardin AK. Gender dimensions of globalization. International Labour Organization, Geneva, 2008. http://www.ilo.org/wcmsp5/groups/ public/@dgreports/@integration/documents/ meetingdocument/wcms_100856.pdf

13 Flynn MA, Wickramage K. Leveraging the domain of work to improve migrant health. Int J Environ Res Public Health 2017;14:1248. doi:10.3390/ ijerph14101248

14 Sirviö A, Ek E, Jokelainen J, Koiranen M, Järvikoski T, Taanila A. Precariousness and discontinuous work history in association with health. Scand J Public Health 2012;40:360-7 doi:10.1177/1403494812450092

15 Spitzer DL, Torres S. Gendered barriers to settlement and integration for live-in caregivers: a review of the literature. Toronto: CERIS Working Paper No. 71; 2008. 
16 Krieger N, Chen JT, Selby JV. Class inequalities in women's health: combined impact of childhood and adult social class--a study of 630 US women. Public Health 2001:115:175-85. doi:10.1016/S0033. 3506(01)00440-1

17 Gamlin JB, Hawkes SJ. Masculinities on the continuum of structural violence: the case of Mexico's homicide epidemic. Soc Polit 2017;25:50-71. doi:10.1093/sp/jxx010

18 Spitzer DL. Work, worries and weariness: towards an embodied and engendered migrant health. In: Spitzer DL, ed. Engendering migrant health Canadian perspectives. UTP, 2011: 23-39. doi:10.3138/9781442696037-003

19 Benach J, Yasui Y, Borrell C, Sáez M, Pasarin MI. Material deprivation and leading causes of death by gender: evidence from a nationwide small area study. J Epidemiol Community Health 2001;55:239-45. doi:10.1136/jech.55.4.239

20 Avato J, Koetti J, Sabates-Wheeler R. Social security regimes, global estimates, and good practices: The status of social protection for international migrants. World Dev 2010;38:455-66. doi:10.1016/j. worlddev.2009.10.003

21 African Region WHO. Health of refugees and migrants. WHO National Office for Africa, 2018. https:// www.who.int/migrants/publications/EURO-report.pdf

22 McLaughlin J, Hennebry J. Pathways to precarity: structural vulnerabilities and lived consequences for migrant farmworkers in Canada. In: Goldring L, Landholt P, eds. Producing and negotiating citizenship: precarious legal status in Canada. UTP, 2013:175-94

23 Migration Integration Policy Index. Health. www. mipex.eu/health
24 Sobritchea C, de Guzman O. Life and death on the move: the sexual and reproductive health status and needs of Filipino women migrant domestic workers. Action for Health Initiatives, 2006.

25 Spitzer DL. Invisible bodies: minority women, nurses, time, and the new economy of care. Med Anthropol Q 2004;18:490-508. doi:10.1525/ maq.2004.18.4.490

26 Sangaramoorthy T. Invisible Americans: migration, transnationalism, and the politics of differences in HIV/AIDS research. Stud Ethn Natl 2008;8:248-66. doi:10.1111/j.1754-9469.2008.00014.x

27 Jones CP. Systems of power, axes of inequity: parallels, intersections, braiding the strands. Med Care 2014;52(Suppl 3):S71-5. doi:10.1097/ MLR.0000000000000216

28 Bourgois P, Holmes SM, Sue K, Quesada I. Structural vulnerability: operationalizing the concept to address health disparities in clinical care. Acad Med 2017;92:299-307. doi:10.1097/ ACM.0000000000001294

29 Diaz E, Ortiz-Barreda G, Ben-Shlomo Y, et al. Interventions to improve immigrant health. A scoping review. Eur J Public Health 2017;27:433-9. doi:10.1093/eurpub/ckx001

30 Hacker K, Anies M, Folb BL, Zallman L. Barriers to health care for undocumented immigrants: a literature review. Risk Manag Healthc Policy 2015;8:175-83. doi:10.2147/RMHP.S70173

31 Özdemir V, Kickbusch I, Coşkun Y. Rethinking the right to work for refugee Syrian healthcare professionals: a call for innovation in global governance. BM/ 2017;357:j2710. doi:10.1136/bmj.j2710

32 Warmington R, Lin D. Healthcare is political: case example of physician advocacy in response to cuts to refugees' and claimants' healthcare coverage under the Interim Federal Health Program. University of Ottawa Journal of Medicine 2014;4:45-8. doi:10.18192/uojm.v4i1.1040

33 Raman S, Woolfenden S, Williams K, Zwi K Human rights and child health. J Paediatr Child Health 2007;43:581-6. doi:10.1111/j.14401754.2007.01147.x

34 Metzl JM, Hansen H. Structural competency: theorizing a new medical engagement with stigma and inequality. Soc Sci Med 2014;103:126-33. doi:10.1016/j.socscimed.2013.06.032

35 Torres S, Balcázar H, Rosenthal L, Labonté R, Fox DJ, Chiu Y. Community health workers in Canada and the US: working from the margins to address health equity. Journal of Critical Public Health 2017;27:533 40. doi:10.1080/09581596.2016.1275523

36 Javanparast S, Windle A, Freeman T, Baum F. Community health worker programs to improve healthcare access and equity: Are they only relevant to low- and middle-income countries? Int J Health Policy Manag 2018;7:943-54. doi:10.15171/ ijhpm.2018.53

37 Bell D, Holliday R, Ormond M, Mainil T. Transnational healthcare, cross-border perspectives. Soc Sci Med 2015;124:284-9. doi:10.1016/j. socscimed.2014.11.014

38 International Organization for Migration. Migrant resource centres: an initial assessment. IOM, 2010. https://publications.iom.int/system/files/pdf/ mrs 40.pdf

Cite this as: $B M / 2019 ; 366: 14256$ http://dx.doi.org/10.1136/bmj.14256 